\title{
Effect of Obesity on Percutaneous Thrombectomy Outcomes in the Treatment of Lower Limb Deep Vein Thrombosis
}

\author{
Emrah Sevgili and Corc Baytaroglu \\ Department of Cardiology, Avcilar Hospital, Istanbul, Turkey
}

\begin{abstract}
Objective: To evaluate the effect of obesity on percutaneous thrombectomy (PT) results for the management of lower limb deep vein thrombosis (DVT).

Study Design: Retrospective cohort study.

Place and Duration of Study: Department of Cardiology, Avcilar Hospital, Istanbul, Turkey, between August 2020 and January 2021.

Methodology: Patients who underwent PT for lower limb DVT were included. Patients' demographic characteristics, operative parameters, and postoperative outcomes were recorded in prospective manner. Patients were divided into two groups, as patients with body mass index (BMI) $<30 \mathrm{~kg} / \mathrm{m}^{2}$ (Group 1) and patients with BMI $\geq 30 \mathrm{~kg} / \mathrm{m}^{2}$ (Group 2). The two groups were compared according to patient demographic properties, intraoperative results, and postoperative outcomes.

Results: Eventually, 62 patients were enrolled into the non-obese group and 30 patients had BMI $\geq 30 \mathrm{Kg} / \mathrm{m}^{2}$. Comparison of the groups demonstrated that the mean operation time and the mean fluoroscopy time were significantly higher in obese patients (121.5 $\mathrm{min}$ vs. $134.5, p=0.017$ and $19.8 \mathrm{~min}$ vs. $25.9 \mathrm{~min}, \mathrm{p}=0.006$, respectively). In addition, the mean hospitalisation period and the mean ICU stay were significantly longer in patients with $\geq 30 \mathrm{~kg} / \mathrm{m}^{2}(p=0.025$ and $p=0.007)$. Postoperative visual analog scale (VAS) score in the first hour was significantly higher in obese patients (2.4 vs. 3.0, $p=0.008)$. The presence of obesity did not have a significant effect on success and complication rates following PT ( $p=0.368$ and $p=0.646)$.

Conclusion: Obesity prolonged operation time and fluoroscopy time during PT. Additionally, obesity was associated with significantly longer hospitalisation period, and ICU stay, and higher VAS score in the first hour following PT.
\end{abstract}

Key Words: Complication, Deep vein thrombosis, Obesity, Percutaneous thrombectomy, Success, VAS score.

How to cite this article: Sevgili E, Baytaroglu C. Effect of Obesity on Percutaneous Thrombectomy Outcomes in the Treatment of Lower Limb Deep Vein Thrombosis. J Coll Physicians Surg Pak 2021; 31(12):1455-1458.

\section{INTRODUCTION}

Deep vein thrombosis (DVT) is a social health problem with one per 1000 annual incidence. ${ }^{1}$ Lower limbs are the most common site of DVT, and untreated DVT is associated with edema, pain, ulcers, and pulmonary embolism. ${ }^{2}$ Anticoagulation therapy is the most accepted treatment option for DVT. However, longlasting anticoagulation administration has risks including irregular use, side effects and interaction with other medicines. ${ }^{3}$ Thus, percutaneous thrombectomy (PT) was introduced into the medical field for management of lower limb DVT. Loffroy and colleagues performed PT for 30 patients with acute iliofemoral DVT, and achieved $86.7 \%$ success rate. ${ }^{4}$

Correspondence to: Dr. Emrah Sevgili, Department of Cardiology, Avcilar Hospital, Istanbul, Turkey

E-mail: emrahsevgilicardio@gmail.com

Received: July 06, 2021; Revised: September 22, 2021;

Accepted: November 01, 2021

DOI: https://doi.org/10.29271/jcpsp.2021.12.1455
In another study by Dumantepe and Uyar, success was $90.7 \%$ for PT in 58 patients. ${ }^{5}$ However, factors affecting success and complications have not been investigated yet.

According to the World Health Organisation, individuals with $\geq 30 \mathrm{Kg} / \mathrm{m}^{2}$ are accepted as obese. Due to reduction of physical activity and changes in dietary habits, obesity has become a pandemic disease. ${ }^{6}$ Many studies focus on the effect of obesity on invasive procedure outcomes. Refahiyat and colleagues claimed that obesity was a risk factor for radiation exposure for health workers during coronary angiography. In another study by Badrudin et al., obesity was found to be a predictive factor for re-hospitalisation after coronary artery bypass surgery. ${ }^{8}$ Although previous studies showed the effect of PT in the management of DVT, no study has investigated the effect of obesity on PT outcomes.

The aim of the present study was to evaluate the effect of the obesity on PT results for the management of lower limb DVT. 
The present study included patients who underwent PT for lower limb (popliteal, femoral, external iliac and common iliac veins) DVT between August 2020 and January 2021. Patient demographic properties and procedure-related parameters were recorded in an electronic database in prospective manner. All PT procedures were done with same technique by the same cardiology team (CB and ES). All patients in the present study had unilateral lower limb DVT, and diagnosis of DVT was revealed by a combination of detailed physical examination and venous duplex ultrasound findings. Patients with bilateral limb DVT, with psychiatric and/or neurologic disease(s), and patients under the age of 18 were excluded from the study. Other exclusion criteria were lack of information about body mass index (BMI) and active infection in percutaneous access area.

Patients' demographic characteristics and thrombus findings were noted. Data about the procedure (operation time and fluoroscopy time) and postoperative period (hospitalisation time, duration of intensive care unit (ICU) stay, decrease of hemoglobin level, postoperative visual analog scale (VAS) in the $1^{\text {st }}$ and $24^{\text {th }}$ hours, success of PT, complications according to Clavien-Dindo classification and follow-up period), were recorded. Procedures with complete removal of thrombus without requiring any additional procedure were considered successful.

All procedures were performed in the same manner under local anesthesia. Before starting the procedure, 5000 IU heparin sodium was administered; and to prevent thromboembolic events, vena cava filter was inserted from the contralateral femoral vein. Percutaneous access was performed from the popliteal vein with an 18 gauge needle under fluoroscopy and ultrasonography guidance, and $8 \mathrm{~F}$ introducer sheath was inserted (Invamed, Ankara, Turkey). Venography was done to evaluate thrombus and patency of vein, and 0.035-size guidewire was advanced beyond the thrombosis. Mechanical thrombectomy was performed until complete removal of thrombus was achieved. At the end of the procedure, venography was routinely performed to evaluate venous patency. Success of PT was re-evaluated at the end of the first month with venous duplexultrasonography.

A total of 92 patients were divided into two groups, as patients with $\mathrm{BMI}<30 \mathrm{Kg} / \mathrm{m}^{2}$ (Group 1) and patients with BMI $\geq 30 \mathrm{Kg} / \mathrm{m}^{2}$ (Group 2). The two groups were compared according to patient demographic properties, intraoperative results, and postoperative outcomes.

The Statistical Package for the Social Sciences version 25 (SPSS IBM Corp., Armonk, NY, USA) programme was used for statistical evaluation. For variable distributions, the Kolmogorov-Simirnov test was used. Independent student t-test was used in comparison of normally distributed parameters and the Mann-Whitney U-test was used for comparison of non-normally distributed variables. Quantitative data are shown as mean \pm standard deviation values. Categorical values were categorised and compared using the $\chi 2$ test or Fisher's Exact test. Qualitative data are presented as numbers and percentages. The data were analysed at $95 \%$ confidence level and $p$ value of less than 0.05 was accepted as statistically significant.

\section{RESULTS}

Ninety-two patients with the mean age 54.6 years and 28.3 $\mathrm{Kg} / \mathrm{m}^{2}$, were enrolled in the study. Most common sites of lower limb DVT were femoropopliteal (40.2\%) and iliofemoral (29.3\%) veins. The mean operation and fluoroscopy time were 125.7 minutes (min) and $21.8 \mathrm{~min}$, respectively. Complications were faced in 16 (17.4\%) cases, and most complications were categorised as Clavien-Dindo grade 1-2 [12 (13.1\%) patients]. Success was achieved in 82 (89.1\%) patients (Table I).

Table I: Demographic data and operative information of all patients.

\begin{tabular}{|l|l|}
\hline & $\mathbf{n}=\mathbf{9 2}$ \\
\hline Age (years)* & $54.6 \pm 16.5$ \\
\hline Sex: & $51(55.4 \%)$ \\
Male & $41(44.6 \%)$ \\
Female & $28.3 \pm 4.1$ \\
\hline BMI (kg/m²)* & $2.0 \pm 0.5$ \\
\hline ASA score* & $51(55.4 \%)$ \\
\hline Smoking status & $15(16.3 \%)$ \\
\hline Diabetes mellitus & $29(31.5 \%)$ \\
\hline Hypertension & $48(52.2 \%)$ \\
\hline Coexistent malignancy & $41(44.6 \%)$ \\
\hline DVT history & \\
\hline Site of DVT: & $27(29.3 \%)$ \\
Ilıfemoral & $17(18.5 \%)$ \\
Popliteal & $11(12.0 \%)$ \\
Femoral & $37(40.2 \%)$ \\
\hline Femoral/popliteal & \\
\hline Side involved: & $46(50.0 \%)$ \\
Right & $46(50.0 \%)$ \\
\hline Left & $125.7 \pm 24.7$ \\
\hline Operation time (min)* & $21.8 \pm 10.0$ \\
\hline Fluoroscopy time (min)* & $3.9 \pm 1.7$ \\
\hline Hospital stay (days)* & $1.6 \pm 1.2$ \\
\hline ICU stay (days)* & $82(89.1 \%)$ \\
\hline Success & $1.1 \pm 1.0$ \\
\hline Decrease of hemoglobin (g/dl)* & $16(17.4 \%)$ \\
\hline Complications: & $12(13.1 \%)$ \\
\hline Clavien-Dindo grade 1-2 & $4(4.3 \%)$ \\
\hline Clavien-Dindo grade 3-5 & $2.6 \pm 1.1$ \\
\hline VAS score*: & $0.9 \pm 0.9$ \\
\hline Postoperative $1^{\text {th }}$ hour & $21.5 \pm 8.7$ \\
\hline Postoperative 24 ${ }^{\text {th }}$ hour & \\
\hline Follow-up (months)* & \\
\hline *Mean \pm standard deviation. BMI: Body mass index, ASA: American society \\
of anesthesiologists classification, DVT: Deep vein thrombosis, ICU: \\
Intensive care unit, VAS: Visual analogue scale. \\
\hline
\end{tabular}

Comparison of preoperative parameters between groups revealed that age, gender, and ASA score were similar between the groups ( $p=0.378, p=0.104$, and $p=0.462$, respectively). In addition, presence of diabetes mellitus, hypertension, coexistence malignancy, and DVT history did not have significant differences $(p=0.948, p=0.223, p=0.238$, and $p=0.289$, respectively). The only statistically significant demographic parameter was mean BMI between the groups $\left(33.1 \mathrm{Kg} / \mathrm{m}^{2}\right.$ vs. $26.0 \mathrm{Kg} / \mathrm{m}^{2} \mathrm{p}<0.001$, Table II).

Table II: Comparison of demographic data between groups according to body mass index. 


\begin{tabular}{|l|c|c|c|}
\hline & BMI <30 (n=62) & BMI $\geq \mathbf{3 0}(\mathbf{n}=\mathbf{3 0})$ & p-value \\
\hline Age (years)* & $55.7 \pm 15.8$ & $52.4 \pm 17.9$ & 0.378 \\
\hline $\begin{array}{l}\text { Gender: } \\
\text { Male }\end{array}$ & $38(61.3 \%)$ & $13(43.3 \%)$ & 0.104 \\
Female & $24(38.7 \%)$ & $17(56.7 \%)$ & \\
\hline BMI $\left(\mathrm{Kg} / \mathrm{m}^{2}\right) *$ & $26.0 \pm 2.6$ & $33.1 \pm 1.6$ & $<\mathbf{0 . 0 0 1}$ \\
\hline ASA score* & $2.0 \pm 0.5$ & $1.9 \pm 0.5$ & 0.462 \\
\hline Smoking status & $37(59.7 \%)$ & $14(46.7 \%)$ & 0.239 \\
\hline Diabetes mellitus & $10(16.1 \%)$ & $5(16.7 \%)$ & 0.948 \\
\hline Hypertension & $17(27.4 \%)$ & $12(40.0 \%)$ & 0.223 \\
\hline Coexistent malignancy & $35(56.4 \%)$ & $13(43.3 \%)$ & 0.238 \\
\hline DVT history & $30(48.4 \%)$ & $11(36.7 \%)$ & 0.289 \\
\hline Duration of symptoms (days)* & $6.8 \pm 3.9$ & $7.1 \pm 4.4$ & 0.760 \\
\hline $\begin{array}{l}* \\
\text { *Mean } \pm \text { standard deviation. BMI: Body mass index, ASA: American society of anesthesiologists }\end{array}$ \\
classification, DVT: Deep vein thrombosis.
\end{tabular}

Table III: Comparison of preoperative data and postoperative results between groups, according to body mass index.

\begin{tabular}{|c|c|c|c|}
\hline & $\begin{array}{c}\text { BMI <30 } \\
(n=62)\end{array}$ & $\begin{array}{c}\text { BMI } \geq 30 \\
(n=30)\end{array}$ & p-value \\
\hline $\begin{array}{l}\text { Site of DVT: } \\
\text { Ilıofemoral } \\
\text { Popliteal } \\
\text { Femoral } \\
\text { Femoral/popliteal }\end{array}$ & $\begin{array}{c}19(30.6 \%) \\
11(17.8 \%) \\
9(14.5 \%) \\
23(37.1 \%)\end{array}$ & $\begin{array}{c}8(26.7 \%) \\
6(20.0 \%) \\
2(6.7 \%) \\
14(46.7 \%)\end{array}$ & 0.642 \\
\hline $\begin{array}{l}\text { Side involved: } \\
\text { Right } \\
\text { Left }\end{array}$ & $\begin{array}{l}34(54.8 \%) \\
28(45.2 \%)\end{array}$ & $\begin{array}{l}12(40.0 \%) \\
18(60.0 \%)\end{array}$ & 0.182 \\
\hline Lesion length $(\mathrm{cm})^{*}$ & $10.8 \pm 1.9$ & $11.2 \pm 1.7$ & 0.343 \\
\hline Operation time (min)* & $121.5 \pm 22.8$ & $134.5 \pm 26.5$ & 0.017 \\
\hline Fluoroscopy time (min)* & $19.8 \pm 9.4$ & $25.9 \pm 10.1$ & 0.006 \\
\hline Amount of blood $(\mathrm{ml})^{*}$ & $259.0 \pm 41.0$ & $249.6 \pm 37.0$ & 0.291 \\
\hline Stenting rate & $10(16.1 \%)$ & $4(13.3 \%)$ & 0.726 \\
\hline Hospital stay (days)* & $3.6 \pm 1.5$ & $4.5 \pm 1.9$ & 0.025 \\
\hline ICU stay (days)* & $1.4 \pm 1.1$ & $2.1 \pm 1.4$ & 0.007 \\
\hline Success & $54(87.1 \%)$ & $28(93.3)$ & 0.368 \\
\hline Decrease of hemoglobin $(\mathrm{g} / \mathrm{dl})^{*}$ & $1.2 \pm 1.0$ & $1.0 \pm 1.1$ & 0.310 \\
\hline $\begin{array}{l}\text { Complications: } \\
\text { Clavien-Dindo grade 1-2 } \\
\text { Clavien-Dindo grade 3-5 }\end{array}$ & $\begin{array}{c}10(16.1 \%) \\
7(11.3 \%) \\
3(4.8 \%)\end{array}$ & $\begin{array}{l}6(20.0 \%) \\
5(16.7 \%) \\
1(3.3 \%)\end{array}$ & $\begin{array}{l}0.646 \\
0.518 \\
0.606\end{array}$ \\
\hline $\begin{array}{l}\text { VAS score*: } \\
\text { Postoperative } 1^{\text {th }} \text { hour } \\
\text { Postoperative } 24^{\text {th }} \text { hour }\end{array}$ & $\begin{array}{l}2.4 \pm 0.8 \\
0.8 \pm 0.8\end{array}$ & $\begin{array}{l}3.0 \pm 1.4 \\
1.1 \pm 1.0\end{array}$ & $\begin{array}{l}\mathbf{0 . 0 0 8} \\
0.174\end{array}$ \\
\hline Re-operation & $1(1.6 \%)$ & $1(3.3 \%)$ & 0.548 \\
\hline Follow-up (months)* & $22.6 \pm 8.6$ & $19.4 \pm 8.6$ & 0.103 \\
\hline
\end{tabular}

Comparison of the groups demonstrated that the mean operation time and the mean fluoroscopy time were significantly higher in obese patients ( $121.5 \mathrm{~min} v s .134 .5 \mathrm{~min}, \mathrm{p}=0.017$ and $19.8 \mathrm{~min} v s .25 .9 \mathrm{~min}, p=0.006$, respectively). In addition, the mean hospitalisation period and the mean ICU stay were significantly longer in patients with $\geq 30 \mathrm{Kg} / \mathrm{m}^{2}(p=0.025$ and $p=$ 0.007 ). Postoperative VAS score in the first hour was significantly higher in obese patients ( 2.4 vs 3.0, $p=0.008$ ); however, VAS score in $24^{\text {th }}$ hour was not significantly different ( $0.8 \mathrm{vs}$. 1.1, $p=0.174)$. Lastly, the presence of obesity did not have a significant effect on success and complication rates following PT ( $p=$ 0.368 and $p=0.646$, respectively).

\section{DISCUSSION}

Percutaneous thrombectomy is increasingly chosen for the treatment of lower limb DVT. However, the number of studies examining the factors affecting PT outcomes is limited. In the present study, the authors aimed to clarify the effect of obesity on PT outcomes for the first time. The authors found that obesity was associated with higher VAS score in the first hour after PT and longer operation time, fluoroscopy time, hospitalisation time and ICU stay. In addition, obesity had no effect on success and complicationsfollowing PT.

The effect of obesity on the duration of surgical procedures is a topic of interest. Michalka and colleagues investigated the effect of obesity on primary hip arthroplasty, and did not find any significant correlation between obesity and operation time. ${ }^{9}$ In contrast, Simsek et al. analysed the impact of obesity on renal stone surgery, and found a positive correlation between obesity and prolonged operative time. ${ }^{10}$ In the present study, the mean operation and the mean fluoroscopy time were significantly longer in obese patients. The authors believe that more difficult positioning for obese patients, difficulties in identifying anatomical landmarks in obese cases, and limited movement of catheters due to acute angulation could be reasons for these results.

No studies examined predictive factors affecting the duration of hospitalization, following the PT procedure. However, Prabhakar et al. found significant correlation between obesity and prolonged hospitalisation stay after coronary artery bypass graft surgery. ${ }^{11}$ Kuduvalli and colleagues stated that BMI $\geq 35$ $\mathrm{Kg} / \mathrm{m}^{2}$ was a predictive factor for longer hospitalisation time and prolonged ventilation time after cardiac bypass surgery. ${ }^{12}$ Similarly, this study also showed longer operation time and ICU stay for obese patients. The present authors believe that difficult postoperative mobilisation and relatively low lung capacity in obese cases were reasons for these outcomes.

VAS is used for the subjective assessment of acute and chronic pain. Auffinger and colleagues studied the impact of obesity on pain, following cervical spine disease surgery, and concluded that obese patients had higher pain VAS scores. ${ }^{13}$ Similarly, Majchrzak et al. focused on postoperative pain, following lung cancer surgery, and the mean VAS was 4.5 and 3.4 in severe obese patients and non-obese patients $(p<0.001) .{ }^{14}$ In accordance, patients with $\geq 30 \mathrm{Kg} / \mathrm{m}^{2}$ had higher VAS score in the first hourfollowing PT.

Studies, which investigated the effect of obesity on success of procedures and complications, provided conflicting results. Davenport and colleagues investigated the $30^{\text {th }}$ day morbidity and mortality after vascular surgeries, and concluded that morbidity and mortality were increased only in patients with $\mathrm{BMI} \geq 40 \mathrm{Kg} / \mathrm{m}^{2} .{ }^{15}$ In contrast, Engel et al. claimed that underweight patients had similar success, and higher mortality and complication rates following coronary artery bypass surgery compared to obese patients. ${ }^{16}$ In the present study, the authors did not determine any significance in terms of success and complications, following PT in the comparison of obese and nonobese patients.

The small patient number and retrospective nature could be considered limitations of this study. However, data was recorded in the electronic database in prospective manner. Additionally, 
the authors did not evaluate the effect of obesity on cost of procedures. Moreover, the authors did not have data about puncture number during percutaneous access and number of maneouvers during clot removal; and the effect of obesity on these parameters could be the subject of another studies.

\section{CONCLUSION}

The present study demonstrated for the first time that obesity prolonged operation time and fluoroscopy time during PT. Additionally, obesity was associated with significantly longer hospitalisation period, and ICU stay, and higher VAS score in the first hourfollowing PT.

\section{ETHICALAPPROVAL:}

The study was approved by the Institutional Ethics Committee of Bezmialem Vakif University, (Date: 06.04.2020; Number: 2020/ 105).

\section{PATIENTS' CONSENT:}

Patients' consents were obtained 24 hours before the procedure.

\section{CONFLICT OF INTEREST:}

The authors declared no conflict of interest.

\section{AUTHORS' CONTRIBUTION:}

ES: Conception, data analyses, interpretation of data, and drafting of manuscript.

CB: Conception, data analyses, and interpretation of data.

\section{REFERENCES}

1. Hong J, Lee JH, Lee JY, Lee JO, Choi WI, Ahn S, et al. Prominent seasonal variation in pulmonary embolism than deep vein thrombosis incidence: $A$ Korean venous thrombosis epidemiology study. Korean J Int Med 2020; 35(3):682. doi: 10.3904/kjim.2018.370.

2. Abu Rahma AF, Mullins DA. Endovascular caval interruption in pregnant patients with deep vein thrombosis of the lower extremity. J Vascular Surg 2001; 33(2):375-8. doi: 10.1067/mva.2001.111488.

3. Palareti G, Cosmi B. Bleeding with anticoagulation therapy-who is at risk, and how best to identify such patients. Thrombosis Haemostasis 2009; 102(2):268-78. doi: 10.1160/TH08-11-0730.

4. Loffroy R, Falvo N, Guillen K, Galland C, Baudot X, Demaistre $E$, et al. Single-session percutaneous mechanical thrombectomy using the aspirex ${ }^{\circledR}$ S device plus stenting for acute iliofemoral deep vein thrombosis: Safety, efficacy, and mid-term outcomes. Diagnostics 2020; 10(8):544. doi: 10.3390/diagnostics10080544.

5. Dumantepe M, Uyar I. The effect of angiojet rheolytic thrombectomy in the endovascular treatment of lower extremity deep venous thrombosis. Phlebology 2018; 33(6):388-96. doi: 10.1177/0268355517711792.

6. Ozgor F, Ucpinar B, Binbay M. Effect of obesity on prone percutaneous nephrolithotomy outcomes: A systemic review. Urol J 2016; 13(1):2471-8.

7. Refahiyat L, Van Oosterhout S, Mulder A, Ten Brock T, Parker JL, Negash A, et al. Impact of patient obesity on radiation doses received by scrub technologists during coronary angiography. Cardiovasc Revasc Med 2018; 19(8):929-33. doi: 10.1016/j.carrev.2018.07.026.

8. Badrudin D, Khaliel F, Cartier R. Obesity paradox in offpump coronary artery bypass surgery: Does it benefit the elderly? Ann Thoracic Surg 2016; 102(6):1974-80. doi: 10.1016/j.athoracsur.2016.05.005.

9. Michalka PK, Khan RJ, Scaddan MC, Haebich S, Chirodian $\mathrm{N}$, Wimhurst JA. The influence of obesity on early outcomes in primary hip arthroplasty. J Arthroplasty 2012; 27(3):391-6. doi: 10.1016/j.arth.2011.05.012.

10. Şimşek A, Özgör F, Akbulut MF, Küçüktopçu O, Berberoğlu AY, Sarılar Ö, et al. Does body mass index effect the success of percutaneous nephrolithotomy? Turk J Urol 2014; 40(2):104-9. doi: 10.5152/tud.2014.66674.

11. Prabhakar G, Haan CK, Peterson ED, Coombs LP, Cruzzavala JL, Murray GF. The risks of moderate and extreme obesity for coronary artery bypass grafting outcomes: A study from the society of thoracic surgeons' database. Ann Thoracic Surg 2002; 74(4):1125-31. doi: 10.1016/s0003-4975(02)03899-7.

12. Kuduvalli M, Grayson AD, Oo AY, Fabri BM, Rashid A. Risk of morbidity and in-hospital mortality in obese patients undergoing coronary artery bypass surgery. Eur J CardioThoracic Sur 2002; 22(5):787-93. doi: 10.1016/s10107940(02)00448-7.

13. Auffinger B, Lam S, Kraninger J, Shen J, Roitberg BZ. The impact of obesity on surgeon ratings and patient-reported outcome measures after degenerative cervical spine disease surgery. World Neurosurg 2014; 82(1-2):e345-52. doi: 10.1016/j.wneu.2013.09.053.

14. Majchrzak M, Brzecka A, Daroszewski C, Błasiak P, Rzechonek A, Tarasov VV, et al. Increased pain sensitivity in obese patients after lung cancer surgery. Front Pharmacol 2019; 10:626. doi: 10.3389/fphar.2019. 00626.

15. Davenport DL, Xenos ES, Hosokawa P, Radford J, Henderson WG, Endean ED. The influence of body mass index obesity status on vascular surgery 30-day morbidity and mortality. J Vascular Surg 2009; 49(1):140-7. doi: 10.1016/j.jvs.2008.08.052.

16. Engel AM, McDonough S, Smith JM. Does an obese body mass index affect hospital outcomes after coronary artery bypass graft surgery? Ann Thorac Surg 2009; 88(6): 1793-800. doi: 10.1016/j.athoracsur.2009.07.077. 